\title{
Reference and predication in Movima
}

\author{
Katharina Haude
}

\section{Introduction ${ }^{1}$}

The issue of whether nouns and verbs are universally distinct syntactic categories comes up again and again in the typological literature (cf. the recent discussion in Linguistic Typology 9). Languages or language families in which this distinction has been a matter of debate include, for instance, Salishan (cf. e.g. Jelinek and Demers 1994; Kinkade 1983), Tongan (cf. Broschart 1997), Tagalog (cf. e.g. Himmelmann 2005a), Mundari (cf. Evans and Osada 2005), and Tupi-Guaranían (Queixalós 2001).

This article demonstrates that Movima, an endangered, unclassified language of Amazonian Bolivia (Haude 2006), should be added to this list. Movima nouns and verbs are distinguished on morphological grounds, and the criteria for a noun-verb distinction in accordance with propositional act functions (Croft 2003) clearly hold: verbs typically function as predicates and nouns typically form part of referring expressions. However, nouns can also function as predicates, and verbs can form part of referring expressions, without any morphological modification. Argument encoding is similar with both nominal and verbal predicates: one of the arguments of a transitive clause is encoded in the same way as a nominal possessor, and the other is encoded in the same way as the single argument of an intransitive clause. Thus, on the syntactic level there is only a weak distinction between nouns and verbs.

While this is nothing new cross-linguistically, Movima furthermore has an apparently unique alignment system, whose explanation may lie in the syntactic similarity of lexical categories. Transitive clauses are organized according to the relative position of the arguments in a referential hierarchy. The argument with the lower-ranking referent has syntactic argument status, while the argument with the higher-ranking referent is encoded like a nominal possessor, i.e. as a phrase-internal modifier. The syntactic flexibility of nouns and verbs, together with the association of possessors with highranking entities, may form the historical basis of this unusual pattern.

This chapter is structured as follows. Section 2 describes the characteristics of affirmative main clauses (for an account of embedded clauses, see 
Haude, forthcoming a): argument encoding and alignment (2.1), referential elements (2.2), and the morphological distinction of nouns and verbs (2.3). Section 3 describes the syntactic flexibility of nouns and verbs, i.e., nouns functioning as predicates (3.1) and verbs occurring in determiner phrases (DPs) (3.2). An interpretation of the findings, which characterize Movima as an 'omnipredicative' language (Launey 1994), is proposed in Section 3.3.

\section{The clause and its parts}

\subsection{Argument encoding and alignment}

The basic constituents of a Movima clause are predicate and argument. The predicate consists of a content word (verb or noun). An argument is expressed by a non-oblique pronoun or determiner phrase (DP), the latter formed by a determiner preceding a content word, as schematized in (1). Constituent order is largely fixed and predicate initial.

\section{(1) Predicate Argument \\ content word [determiner + content word]}

Intransitive clauses are defined by the fact that they may contain maximally one overt argument; in (2), it is represented by a DP (in square brackets; the phonetic representation in the third line will become relevant below).

$$
\begin{aligned}
& \text { kat-pit [is chinała] } \\
& \text { break-half ART.PL manioc } \\
& \text { [kap }{ }^{\mathrm{m}} \mathrm{pif?}^{\mathrm{n}} \text { ?is } \quad \widehat{\mathrm{t}} \text { jinała] }
\end{aligned}
$$

'The manioc roots are broken in halves. ${ }^{3}$

When the argument of an intransitive clause is represented by a bound pronoun, this pronoun is cliticized to the predicate through what I term 'external cliticization' (represented by a double dash), as in (3).

(3) kat-pit--as

break-half--3N.AB

['kap? mpitas]

'It was broken in halves.' 
External cliticization (in contrast to 'internal cliticization', which occurs in transitive clauses and will be described below) is characterized by the fact that when the host ends in a consonant, this consonant forms the syllable onset of the vowel-initial cliticized pronoun (cf. Haude 2006: 101-103). This can be observed by comparing the phonetic representations in (2) and (3) above: in coda position (2), /t/ is realized as a complex glottalized consonant, [t $\left.\mathrm{t}^{\mathrm{n}}\right]$, which attracts stress; in onset position (3), /t/ is realized as $[\mathrm{t}]$. The vowel-initial referential element, furthermore, is preceded by a glottal stop when not cliticized, as in (2).

The argument of an intransitive clause can also be represented by a free pronoun, which is not cliticized and typically occurs in topic position, i.e. preceding the predicate:

(4) i'ne de $<$ ja: > jal

PRO.F cook $\langle\mathrm{MD} \sim$

'She cooks.'

When the argument is known from the context, it can be omitted, as in (5):

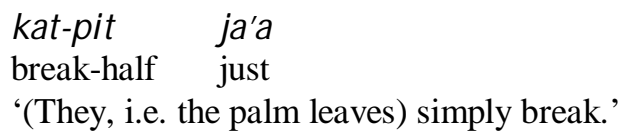

In sum, intransitive clauses have the property that they take maximally one overt argument, which can be expressed as a DP, as an independent pronoun, or as an externally cliticized bound pronoun, and which may be omitted.

Transitive clauses, in contrast, are characterized by the fact that they may contain two overt arguments, which typically both follow the predicate. Their linear order corresponds to the position of their referents in the referential hierarchy in (6), which basically involves person and topicality: the higher-ranking participant is encoded first, with the lower-ranking participant encoded in second position after the predicate.

(6) $1>2>3$ topic (given) $>3$ nontopic (new)

Semantic roles are indicated through direct or inverse marking on the predicate: when the actor outranks the undergoer in a two-participant event, the verb is marked as direct (7); when the undergoer outranks the actor, the verb is marked as inverse (8). 
(7)
fow-na= y'di [os kare:ta $]$
pull-DR=1PL ART.N.PST oxcart
'We pulled the oxcart.'

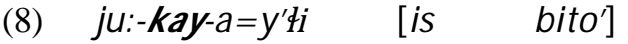
scold-INV-LV=1PL ART.PL old_person
'The old people scolded us.'

Due to the hierarchy-based constituent order and the 'remapping' effect of the direct/inverse opposition (cf. Zúniga 2006: 62), it is difficult to assign uncontroversial labels to the nominal constituents in a Movima transitive clause. Based on their position in the referential hierarchy, I will refer to the argument encoded in first position after the predicate as 'Proximate Argument' (short: PROX) and to the argument encoded in second position after the predicate as 'Obviate Argument' (short: OBV). ${ }^{4}$ Apart from linear order, the formal differences between PROX and OBV are as follows.

PROX is obligatorily realized. The absence of a pronominal PROX enclitic from the predicate of a transitive clause indicates the first person singular, as shown in (9). PROX is also expressed after the predicate when there is a coreferential free pronoun in topic position, as in (10).

(9) jiwa-te:-na $=\varnothing \quad$ [is chujat-di $]$ come-CO-DR=1SG ART.PL motacú-CL.seed

'I brought motacú nuts.'

(10) i'ne jiwa-łe-na='ne

PRO.F come-CO-DR=3F

'She (was the one who) brought (it).'

PROX is phonologically attached to the predicate through 'internal cliticization'. This process creates a structure whose stress properties are those of a prosodic word: when a monosyllabic element is internally cliticized, this causes stress shift, stress moving one position to the right. When the host has an open penultimate syllable, this syllable loses its original lengthening. The phonetic representations in (11) illustrate the stress shift and the shortening of the vowel. 
(11)

$$
\begin{aligned}
& \text { a. } \text { aya:-na= } \varnothing \text {--us } \\
& \text { wait_for-DR=1SG--3M.AB } \\
& \text { [a'ja:na?us] } \\
& \text { 'I wait for him.' }
\end{aligned}
$$

b. aya-na $=$ us

wait_for-DR=3M.AB

[aja'na?us]

'He waits for (him/her/it/them).'

Internally cliticized elements furthermore require a preceding vowel: when the host ends in a consonant, the linking vowel -a is inserted, as illustrated in (12). Example (12) also demonstrates that internal cliticization (unlike external cliticization) involves determiners in the same way as pronouns.

$$
\begin{array}{llll}
\text { kay-a-poj-a }=[\mathrm{us} & \text { itila:kwa }] & \text { [os } & \text { pa:ko }] \\
\text { eat-DR-CAUS-LV=ART.M } & \text { man } & \text { ART.N.PST } & \text { dog }
\end{array}
$$

'The man fed the dog.'

With these properties, the encoding of PROX is identical to the encoding of a nominal possessor. This is illustrated in (13), where a pronoun is attached through internal cliticization to a consonant-final noun augmented by the linking vowel.
(13) as powol-a $=\mathrm{us}$
ART.N straw_mat-LV=3M.AB
'his straw mat'

Obligatorily possessed nouns (e.g. kinship terms, body-part terms) without an internally cliticized element are interpreted as having a first person singular possessor (14), in the same way as unmarked bivalent verbs are interpreted as having a first person singular PROX argument (see [9] above). ${ }^{5}$

$$
\begin{aligned}
& \text { (14) kinos majni }=\varnothing \\
& \text { ART.F.AB offspring }=1 \mathrm{SG} \\
& \text { 'my daughter' }
\end{aligned}
$$

In contrast to PROX, OBV has the same formal properties as the single argument of an intransitive clause, described above. When expressed as a $\mathrm{DP}$, as in (7) and (8) above, it is phonetically independent; when realized as a bound pronoun, it is attached to the preceding constituent (the predicate with the PROX enclitic) through external cliticization, as in (15) below. It is not obligatorily realized, as shown in (16); and OBV can also be expressed as a free pronoun preceding the predicate, as in (17). 
(15)

dewaj-na $=\mathrm{n}--i s$

see-DR=2--3PL.AB

'You see them.'

(16) jayna tikoy-na $=$ us

DSC kill-DR $=3 \mathrm{M} . \mathrm{AB}$

'Then he killed (it, i.e. the tapir).'

(17) a'ko jayna yey-na= is

PRO.N DSC want-DR=3PL.AB

'This, then, is what they want.'

Table 1 lists the formal properties that distinguish the PROX argument and the possessor, on the one hand, from OBV and the single argument of an intransitive clause, on the other.

Table 1. Formal properties of argument and possessor encoding

\begin{tabular}{ll}
\hline PROX and possessor & OBV and argument of intransitive clause \\
\hline Internal cliticization $(=):$ & External cliticization $(--)$ : resyllabifica- \\
stress shift, epenthetic /a/ & tion, no stress shift, no epenthetic /a/ \\
Pronouns and articles are cliticized & Only pronouns are cliticized \\
Obligatory & Not grammatically obligatory \\
\hline
\end{tabular}

To sum up, the argument of a transitive clause that refers to the participant higher in the referential hierarchy is encoded in the same way as a nominal possessor; the argument with the lower-ranking referent, in contrast, is encoded in the same way as the single argument of an intransitive clause.

Moreover, as I have demonstrated elsewhere in more detail (Haude, in press; Haude, forthcoming b), OBV is syntactically privileged, whereas there is no evidence that PROX has access to any syntactic operations to which OBV does not have access. In particular, as illustrated by the following elicited examples (based on [12] above), OBV can be relativized (18), while in order to relativize the participant encoded as PROX in a transitive clause, a valency-decreasing operation is needed, marked by the particle kaw (19). Here, the former PROX becomes the single argument of the now intransitive clause, while the former OBV is demoted to adjunct status (marked as oblique). 
(18) $[\mathrm{os}$ pa:ko] di

kay-a-poj-a $=[$ us

itila:kwa]

ART.N.PST dog

REL eat-DR-CAUS-LV=ART.M man

'the dog that the man fed'

(19) [us itila:kwa] di

[n-os

man

OBL-ART.N.PST dog

'the man who fed the dog'

Interestingly, this operation works with nouns as well (see Haude, forthcoming b): a noun combined with the particle kaw denotes the possessor of an entity, not the entity itself, and cannot be marked for a possessor anymore by an internal enclitic: kinos kaw majni 'his/her/their mother' (cf. [14] above).

\subsection{Referential elements}

The class of referential elements comprises articles, free pronouns, bound pronouns, and demonstratives. ${ }^{6}$ These all indicate the referent's gender, number, and presence at or absence from the speech situation. Articles (see Table 2) additionally indicate when an absent referent has ceased to exist (cf. Haude 2004).

Table 2. Articles ${ }^{7}$

\begin{tabular}{llll}
\hline & Presential/generic & Absential & Past (ceased to exist) \\
\hline ART.M & us & kus & us \\
ART.F & i'nes & kinos & isnos \\
ART.N & as & kos & os \\
ART.PL & is & kis & is \\
\hline
\end{tabular}

Articles are obligatorily followed by a content word, together with which they form a DP, as illustrated in (20). They do not distinguish between definite and indefinite reference.

(20) i'nes kwe:ya 'the/a woman (present)' kinos kwe:ya 'the/a woman (absent, in existence)'

isnos kwe:ya 'the/a woman (absent, deceased)' 
Plural number is used for more than one countable entity as well as for liquids and masses (cf. Haude 2006: 150-151). Gender is semantically determined: humans are distinguished according to natural gender; non-humans are classed as neuter (21).

$\begin{array}{llll}\text { masculine: } & \text { us dichi:ye } & \text { 'the/a boy' } \\ \text { feminine: } & \text { i'nes } & \text { dichi:ye } & \text { 'the/a girl' } \\ \text { neuter: } & \text { as wa:ka } & \text { 'the/a cow' }\end{array}$

Presence at the speech situation implies that the referent is more or less within calling distance, for example in the same house or compound. The presential forms of the referential elements are also used for entities whose location is common knowledge, e.g. places:

\section{(22) as Kochawamba 'Cochabamba (town in Bolivia)'}

With these properties, the article clearly has the function of establishing reference, be it specific or generic, definite or indefinite.

\subsection{Nouns and verbs: morphological characteristics}

As the point of departure for examining the formal differences between nouns and verbs in Movima, I define nouns as belonging to the class of words whose meaning is prototypically associated with entities, and verbs as words whose meaning is prototypically associated with events. The main formal criteria for distinguishing nouns from verbs are morphological. They are quite subtle, due to the fact that the typical word-class defining morphological categories (cf. e.g. Schachter 1985) are lacking: nouns are not morphologically marked for gender, number, or case, and the typical verbal categories tense, aspect, and mood are not morphologically marked on verbs.

The distinction between verbs and nouns can be recognized through morphological tests: there are morphemes that can be combined with nouns but not with verbs (cf. Haude 2006: 106-111). In particular, nouns undergo reduplication in order to form the predicate of an embedded clause, as illustrated in (23) with the noun tolkosya 'girl'. Verbs, in turn, need to take the suffix -wa to function as predicates of embedded clauses, as shown in (24). (All embedded predicates are obligatorily possessed action/state nominals.)

(23) n-os

tolkos $<$ ya $>$ ya $=$ sne

OBL-ART.N.PST $\operatorname{girl}<\mathrm{NMZ}>=3 \mathrm{~F} . \mathrm{AB}$ 
'when she was a girl' (lit.: 'at her former being a girl')

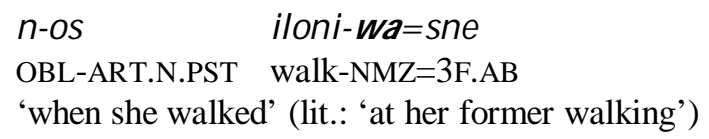

According to this criterion, property-denoting words (semantic adjectives) can be identified as morphological nouns, since they undergo reduplication in embedding or negation; in (25), this is illustrated with the word tochik 'small'.

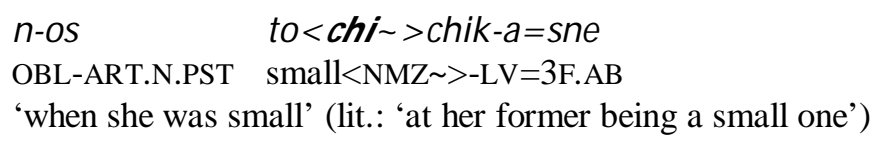

The distinction of bivalent verbs from nouns and monovalent verbs is more straightforward, since bivalent verbs are always overtly marked as either direct or inverse. In those cases in which nouns contain the direct morpheme, syntactic criteria distinguish them from bivalent verbs, as will be illustrated in (35) below.

\section{Nouns and verbs: distributional characteristics}

\subsection{Predicate nominals}

There is no copula in Movima affirmative clauses, and nouns can function as predicates without morphological modification. A rough text count showed that predicate nominals constitute only about $10 \%$ of the total number of predicates. However, unless morphological tests are carried out (cf. 2.3 above), it is often impossible to identify a monovalent predicate on formal grounds as either a verb or a noun. In particular, semantic adjectives occur more often as predicates (26) than inside a DP (27), even though morphological tests identify them as nouns (see [25] above).

(26) $k a: w-e \quad$ [is majni $=\varnothing]$ much-CL.person ART.PL child=1SG

'I have many children.' (lit.: 'My children are many.')

(27) ji<wa: > wa [us bi:jaw] come $\langle\mathrm{MD} \sim \quad$ ART.M old 
'The old (man) came.'

Clauses with unpossessed predicate nominals are formally identical to clauses with monovalent verbal predicates. The argument of such a clause can be expressed as a phonologically independent DP (28); as an externally cliticized pronoun (29); as a free pronoun in topic position (30); and it can be omitted when it is known from the context (31). (In [28-31], the predicate nominals are rendered in bold print.)

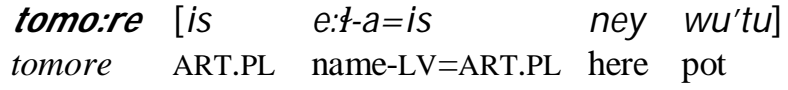

(29) tolkosya--sne

girl--3F.AB

'She (was a) young woman.'

(30) a'ko lopa:vos

PRO.N manioc_stem

'This (is a) manioc stem.'

(31) jayna mo'incho:but

DSC manioc_mass

'(It was) already fermented manioc mass.'

As the examples show, predicate nominals denote the state of being the entity denoted by the noun. I am aware of only one type of case in which the predicative meaning of a noun clearly differs from its meaning inside a DP. This involves words denoting languages, such as kaste 'Spanish' or chonsine $\$$ 'native language' (see Evans and Osada 2005 for a similar example). When occurring inside a DP, as in (32a), these words denote the language itself; when functioning as predicate, in contrast, they denote the act of speaking the language, as in (32b).
a. iwa:ni--sne [n-as chonsinet] speak--3F.AB OBL-ART.N native_language 'she speaks in the native language'
b. chonsinet--isne
native_language--3F.AB
'She speaks the native language.' 
As was illustrated in 2.1 above, the possessor of a noun is encoded in the same way as PROX. Therefore, it can be expected that clauses with a possessed predicate nominal are identical to transitive clauses with a bivalent verbal predicate. However, this is not entirely the case: the argument of a possessed predicate nominal can only be expressed by a free pronoun in topic position, as in (33).
(33) ka<ya: >y-ak, a'ko nono=n eat $<$ IRR $>$-IRR PRO.N pet $=2$ 'May (it) eat, it's your pet!'

The elicited example (34b), contrasted with (34a), shows that it is ungrammatical to express the argument of a clause with a possessed predicate nominal as an externally cliticized pronoun:
a. asko pa:ko=us
PRO.N.AB dog $=3 \mathrm{M} . \mathrm{AB}$
'It is his dog.'
b. *pa:ko=us--k-as
$\operatorname{dog}=3 \mathrm{M} \cdot \mathrm{AB}-\mathrm{-OBV}-3 \mathrm{~N} \cdot \mathrm{AB}$
('It is his dog.' $)^{8}$

This syntactic restriction on argument encoding in clauses with possessed predicate nominals serves as a criterion for distinguishing obligatorily possessed nouns from bivalent verbs in those cases where these are morphologically similar. On inherently monovalent verbal bases (cf. Haude 2006: 340344 ), the direct marker -na serves as a nominalizer that derives a locationdenoting noun. When this noun functions as a predicate, its argument must be encoded by a free pronoun in topic position, as in (35a). The ungrammatical example (35b) was elicited to confirm this pattern.
a. $a^{\prime} k o \quad$ as-na $=[\mathrm{kus} \quad$ ya:yak $=\varnothing], \quad[$ as
Kachweli:ta]
PRO.N sit-DR=ART.M.AB uncle $=1 \mathrm{SG}$ ART.N Cachuelita
'This is where my uncle lives, Cachuelita.' (lit. 'This is my uncle's sitting place, Cachuelita.')

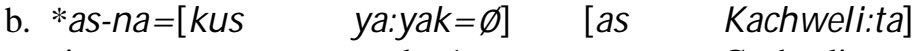
sit-DR=ART.M.AB uncle=1SG ART.N Cachuelita
(intended meaning: 'My uncle lives in Cachuelita,' lit.: 'Cachuelita is my uncle's sitting place.')
As is summed up in Table 3, monovalent verbs and nonpossessed nouns have identical syntactic properties, which is in line with the fact that they are 
also difficult to distinguish morphologically. Bivalent verbs and possessed nouns differ from the former two in that they are combined with an internally cliticized referential element. Unlike the case of bivalent verbal predicates, however, the argument of a clause with a possessed predicate nominal has restricted distributional possibilities: it cannot be expressed as an externally cliticized pronoun.

Table 3. Argument encoding in nominal and verbal clauses

\begin{tabular}{llll}
\hline Predicate type & $\begin{array}{l}\text { Takes internal } \\
\text { clitic (=) }\end{array}$ & $\begin{array}{l}\text { Can take external } \\
\text { clitic (--) }\end{array}$ & $\begin{array}{l}\text { Can take free pronoun } \\
\text { in topic position }\end{array}$ \\
\hline $\begin{array}{l}\text { Monovalent verb / } \\
\text { nonpossessed noun }\end{array}$ & no & yes & yes \\
Bivalent verb & yes & yes & yes \\
Possessed noun & yes & no & yes \\
\hline
\end{tabular}

\subsection{Verbs in DPs}

When a DP contains a verb instead of a noun, as is the case in approximately $5 \%$ of my text corpus, it refers not to an event, but to a participant in an event. The role the participant has in the event is specified by the verb's argument structure. When the verb is bivalent, the DP refers to the participant that is encoded as OBV when the verb functions as predicate. This means that a DP containing a direct-marked verb refers to the undergoer in the event, as in (36), and a DP containing an inverse-marked verb refers to the actor, as in (37). Gender, number, and spatio-temporal properties of the referent are indicated by the article.

$$
\begin{array}{llll}
\text { nokowa } \quad \text { rime } \$ \text {-na= } \varnothing \quad \text { [is } & \text { yey- } n a=n] \\
\text { right_now } & \text { buy-DR=1SG } & \text { ART.PL } & \text { want-DR=2 } \\
\text { 'Now I'll buy (the things) you want.' } &
\end{array}
$$

$$
\begin{array}{lllll}
\text { jayna } & \text { ji<wa: > wa } & \text { [us } & \text { rey } & \text { yey-kay-a=n] } \\
\text { DSC } & \text { come<MD > } & \text { ART.M } & \text { MOD } & \text { want-INV-LV=2 } \\
\text { 'The one who loves you, you know, has come already. }{ }^{9}
\end{array}
$$

Similarly, when the verb inside a DP is monovalent, the DP refers to the participant that is encoded as the single argument when the same verb functions as a predicate (although see below). The DP in (38) refers to the actor in the event, which is encoded as OBV when the verb deja:jal is a predicate 
(cf. (4) above); the DP in (39) refers to the undergoer, in line with the role of $\mathrm{OBV}$ when the verb katpit functions as predicate (cf. (3) above).

$$
\begin{array}{lll}
\text { kiro' } \quad[\text { kis } & \text { de }<\text { ja: } \sim \text { jal }] \\
\text { DEM.PL.AB } & \text { ART.PL.AB } & \text { cook<MD > } \\
\text { 'There are (people who) cook.' }
\end{array}
$$

$\begin{array}{llllll}\text { jayna } & \& & \text { vel-na }=\varnothing & \text { [os } & \text { rey } & \text { kat-pit }] \\ \text { DSC } & 1 & \text { look_at-DR=1SG } & \text { ART.N.PST } & \text { MOD } & \text { break-half } \\ \text { 'Then I looked at the broken (part), you see.' } & \end{array}$

In contrast to bivalent verbs, there are a few exceptional cases with respect to the interpretation of monovalent verbs inside DPs. In particular, these include all verbs that contain an incorporated argument (often represented by a classifier-like element, see Haude 2006: 283-286). These verbs are composed of a transitive root, an incorporated nominal element, and the direct morpheme. As predicates, they are monovalent, and the argument represents the actor, as illustrated in (40a). However, when they occur inside a DP, the DP refers to the undergoer, and the actor is encoded as PROX/possessor, as in $(40 \mathrm{~b}) .{ }^{10}$
a. loj-a:-'oj--is wash-DR-CL.clothes--3PL.AB 'They wash clothes.'
b. kis loj-a-'oj-a= is
ART.PL.AB wash-LV-CL.clothes-LV=3PL.AB
'their laundry' (not: 'the [ones who] wash clothes')

The most important fact to note is that a DP containing a verb never refers to an event, but to a participant in an event, whose characteristics are specified by the determiner. Reference to events, in contrast, is carried out with derived forms. The embedded clause in (41) and the negated clause in (42) illustrate an event-denoting expression derived from a verb (an example of a state-denoting predicate nominal was given in (23) above):

$\begin{array}{lll}\text { (41) no-kos } & \text { joyaj-wa=sne } & \text { ney }\end{array}$

'when she arrived here (earlier today)' (lit.: 'at her earlier arriving here') 
(42) kas joyaj-wa $=$ sne

NEG arrive-NMZ $=3 \mathrm{~F} . \mathrm{AB}$

'She didn't arrive.' (lit.: 'Her arriving is/was not.')

Unlike verbs, event- and state-denoting forms can only be combined with the neuter article, as in (41) and (23) above. Furthermore, with these forms, the article only has a temporal, not a spatial interpretation: as illustrated in (41), the absential article refers to a time on the same day, but before the moment of speaking (cf. Haude 2004: 83; 2006: 168-171). Verbs, in contrast, can be combined with all forms of the article, in accordance with the referential properties of the event participant.

\subsection{Interpreting the syntactic flexibility of nouns and verbs}

With the properties described above, Movima fulfils the requirements of an 'omnipredicative' language (Launey 1994; 2002: 114-118). In a language of this type, while nouns and verbs can be morphologically distinct categories, both word classes "should be able to function directly as predicates, and should have equal potential to form referring expressions through $[\ldots]$ at least the addition of some sort of determiner" (Evans and Osada 2005: 361). ${ }^{11} \mathrm{~A}$ characteristic property of omnipredicative languages is that nouns functioning as predicates are interpreted as 'be X', and that the addition of a determiner to a noun or verb produces "no further semantic increment than that accompanying relativization in English" (Evans and Osada 2005: 362), i.e., '(the) one that (is) X'. As could be seen in Sections 3.1 and 3.2, this corresponds to the interpretations of nouns in predicate function and verbs inside DPs, respectively, in Movima.

The question is, however, whether a semantic increment is involved at all when verbs occur in a referential expression in Movima. It may also be possible to interpret all verbs as nominal expressions that characterize a participant in an event rather than denoting the event itself (cf. Sasse 1993: 655 on Salishan and Tagalog). A monovalent verb like de ja:jal (cf. (4), (38) above) may have the meaning 'one who cooks' rather than '(to) cook'; a verb like katpit in (2-3), (5), and (39), may have the meaning 'broken (one)' rather than 'break'. In the same way as nouns, then, their occurrence as a predicate may trigger an equational reading, i.e., a verb in predicate function has the meaning 'be (the) one who does/undergoes X'.

For bivalent verbs, this interpretation is equally possible, since PROX is encoded in the same way as a possessor. A direct bivalent verb can be inter- 
preted as an undergoer-oriented participle, i.e. yeynan in (36) as 'your wanted X'; and an inverse-marked verb can be interpreted as an actororiented participle, i.e. yeykayan in (37) as 'your wanting/loving X'. As with predicate nominals, when functioning as predicates, these verbs create equational clauses meaning 'your wanted $\mathrm{X}$ is' and 'your wanting/loving $\mathrm{X}$ is', respectively. Further research may reveal that the direct and inverse markers originate from nominalizers that derive oriented participles (cf. Sasse 1993: 660-661 on Semitic), as is suggested by the nominalizing function of the direct marker on certain verbal bases (see (35) above).

This interpretation of verbs helps to understand the cross-linguistically unusual fact that in Movima, the argument representing the lower-ranking participant (OBV) aligns with the single argument of an intransitive clause and is syntactically privileged: OBV can be interpreted as the only syntactic argument of an intransitive, equational clause, while PROX has the status of a phrasal modifier. In this way, all Movima clauses can be characterized as being of the Aristotelian type, consisting of a predicate and a subject (cf. Sasse 1991). Examples (7) and (8) above can accordingly be paraphrased by something like 'the oxcart was our pulled one' and 'the old people were our scolding ones', respectively. The fact that PROX is associated with the participant high in the referential hierarchy can perhaps be explained by its formal analogy to a possessor in a DP: a prototypical possessor ranks higher than the entity possessed by it.

While diachronically, this scenario may indeed be responsible for the syntactic patterns of Movima, it cannot be entirely maintained for the synchronic situation. The syntactic differences between possessed nouns and bivalent verbs in predicate function (cf. Table 3 above) prove that synchronically, nominal and verbal predicates do not have an identical syntactic status. Furthermore, semantic differences in the interpretation of certain content words depending on their syntactic position (cf. [32], [40] indicates that to a certain degree, conversion does exist in Movima, which would not be the case if the semantics of content words were independent of syntactic position (on this issue see Croft 2001: 70-75; Croft 2005: 432-434; Evans and Osada 2005: 367-375; Himmelmann 2005b: 131).

\section{Conclusion}

In Movima, all content words can function as predicates and, in combination with a determiner, form part of referential expressions. According to my interpretation, and apart from very few exceptions, both nouns and verbs 
retain their meaning independently of their function in the clause. This phenomenon has also been observed in other areally and genetically unrelated languages, where it has given rise to concepts such as 'omnipredicativity' (Launey 1994), 'flexibility' (Hengeveld 1992), or 'syntactic uniformity' (Himmelmann 2008).

Movima seems to represent a particularly strong example of this language type. The determiner, which indicates semantic and spatio-temporal properties of the referent, provides clear evidence that verbs in referring expressions denote event participants and not events, an interpretation that can be extended to verbs in predicate function. A further feature of Movima, briefly mentioned above, is that both bivalent verbs and possessed nouns undergo the same valency-decreasing operation, which emphasizes their similar syntactic status. The existence of a nominalizing function of the direct marker on certain verbal bases points to a possible origin of synchronically bivalent verbs from oriented nominalizations.

Movima syntax furthermore displays a feature that has so far not been described for any other language: the expression of the arguments in a transitive clause is determined by the position of the event participants in a referential hierarchy, and semantic roles are indicated through direct and inverse morphology on the predicate. This leads superficially to an unusual alignment split, with direct clauses patterning ergatively and inverse clauses patterning accusatively. The present analysis, under which synchronic transitive clauses are interpreted as basically intransitive, equational clauses with a possessor-like modifier on the predicate, may contribute to an explanation of this apparently unique pattern.

\section{Notes}

1. This article was prepared within the Movima documentation project financed by the DoBeS programme of the Volkswagenstiftung. The presented data were collected within the Spinoza program 'Lexicon and Syntax' at the Radboud University Nijmegen. I am very much indebted to the Movima speakers for teaching me their language. For discussions on the topic presented here I owe special thanks to Werner Drossard, Spike Gildea, Theresa Hanske, Nikolaus Himmelmann, Francesc Queixalós, and Hans-Jürgen Sasse. I thank Eva van Lier and Loretta O'Connor, as well as the reviewers Peter Arkadiev and Hein van der Voort and the editors of the volume, for their detailed comments on the manuscript. Any remaining errors are my own responsibility. 
2. The data on which the study is based were collected in Santa Ana del Yacuma between 2001 and 2007. Unless otherwise indicated, all examples stem from spontaneous discourse. Symbols (partly adapted from the Leipzig Glossing Rules) are: = internal cliticization; -- external cliticization; <> infix; $\sim$ reduplication. Abbreviations in glosses are: 1 first person, 2 second person, 3 third person, AB absential, ART article, CAUS causative, CL classifier, CO coparticipant, CTF counterfactual, DEM demonstrative, DET determiner, DP determiner phrase, DR direct, DSC discontinuous, EV evidential, F feminine, INV inverse, IRR irrealis, LV linking vowel, M masculine, MD middle, MOD modal, $\mathrm{N}$ neuter, NEG negative particle, NMZ action/state nominalization, OBL oblique, OBV obviative marking, PST past, PL plural, PRO free pronoun, REL relativizer, SG singular.

3. Tense is not always overtly encoded in Movima; in the translations of the examples, tense is chosen according to the original context.

4. See Bickel (in press) for first using the labels 'proximative' and 'obviative' for the nominal constituents in Movima. These labels stem from the description of Algonquian inverse systems and refer to the formal distinction of third-person arguments based on their discourse status. The capital letters in 'Proximate Argument' and 'Obviate Argument' used here are intended to show that, while semantically/pragmatically based, they refer to formal categories (cf. Haspelmath 2007: 125).

5. Nouns that are not obligatorily possessed are marked for a first-person singular possessor by a proclitic element $d$; this marker is optional with obligatorily possessed nouns and, as in (39), with bivalent predicates (cf. Haude 2006: 234; 271-272).

6. Only articles will be treated here in detail. For the system of demonstratives, see Haude (2006: 174). Free pronouns are glossed as PRO, bound pronouns are not glossed for their category, but simply for the person they mark.

7. Some presential and past forms of the article are homophonous with absential forms of bound pronouns.

8. The 'obviative' marker $\mathrm{k}$ - on a third-person bound OBV pronoun occurs whenever PROX is or includes a third person, and would therefore be expected here.

9. The occurrence of TAM- or discourse particles inside a DP is common, also when the DP contains a noun (cf. Haude 2006: 510).

10. It is possible that inside a DP, these verbs are interpreted as right-headed nominal compounds. Alternatively, it may be the direct marker that is responsible for the changed 'argument structure' of these verbs when occurring in a DP. Two other exceptions, which behave like argument-incorporating verbs, are the monovalent verbs samna 'weave' and ya:lo:we 'drink'. The verb samna is problematic in that it is the only verb with the form of a direct bivalent verb (root $+\mathrm{DR})$ that behaves like a monovalent verb when functioning as predicate. The irregularity of the verb ya:lo:we may have to do with its historical com- 
plexity, which may also have involved incorporation: ya:- 'under(?)', -lo 'CL.liquid' and -we 'CL.person'.

11. See also Queixalós (2006) on Tupi-Guaranían, including a discussion of the diachronic instability of omnipredicative systems.

\section{References}

Bickel, Balthasar

in press Grammatical relations typology. In The Oxford handbook of linguis-

Broschart, Jürgen

tic typology, Jae-Jung Song (ed). Oxford: Oxford University Press.

1997 Why Tongan does it differently: Categorial distinctions in a language without nouns and verbs. Linguistic Typology 1: 123-165.

Croft, William

2001 Radical Construction Grammar. Oxford: Oxford University Press.

2003 Typology and Universals (2nd edn). Cambridge: Cambridge University Press.

2005 Word classes, parts of speech, and syntactic argumentation. Linguistic Typology 9 (3): 431-441.

Evans, Nicholas and Toshiki Osada

2005 Mundari: The myth of a language without word classes. Linguistic Typology 9 (3): 351-390.

Haspelmath, Martin

2007 Pre-established categories don't exist: Consequences for language description and typology. Linguistic Typology 11 (1): 119-132.

Haude, Katharina

2004 Nominal tense marking in Movima: Nominal or clausal Scope? In Linguistics in The Netherlands 2004, Cornips, Leonie and Jenny Doetjes (eds.), 80-90. Amsterdam/Philadelphia: Benjamins.

2006 A grammar of Movima. Ph. D. diss., Radboud Universiteit Nijmegen. in press Hierarchical alignment in Movima. International Journal of American Linguistics.

forthc. a Embedded clauses in Movima. In Subordination in South American Languages, Rik van Gijn, Katharina Haude, and Pieter Muysken (eds.).

forthc. b The intransitive basis of Movima clause structure. In Ergativity in Amazonia, Spike Gildea and Francesc Queixalós (eds.).

Hengeveld, Kees

1992 Nonverbal Predication. Theory, Typology, Diachrony. Berlin/New York: Mouton de Gruyter.

Hengeveld, Kees and Jan Rijkhoff 
2005 Mundari as a flexible language. Linguistic Typology 9 (3): 406-431. Himmelmann, Nikolaus P.

2005a Tagalog. In The Austronesian Languages of Asia and Madagascar, Adelaar, Alexander and Nikolaus P. Himmelmann (eds.), 350-376. London/New York: Routledge.

2005b The Austronesian Languages of Asia and Madagascar: Typological Characteristics. In The Austronesian Languages of Asia and Madagascar, Alexander Adelaar and Nikolaus P. Himmelmann (eds.), 110-181. London/New York: Routledge.

2008 Lexical categories and voice in Tagalog. In Voice and Grammatical Functions in Austronesian Languages, Peter Austin and Simon Musgrave (eds.), 247-293. Stanford: CSLI.

Jelinek, Eloise and Richard A. Demers

1994 Predicates and pronominal arguments in Straits Salish. Language 70: 697-736.

Kinkade, M. Dale

1983 Salish evidence against the universality of 'noun' and 'verb'. Lingua 60: $25-40$.

Launey, Michel

1994 Une Grammaire Omniprédicative. Paris: CNRS Editions.

2002 Compound nouns vs. incorporation in Classical Nahuatl. In Problems of Polysynthesis, Nicholas Evans and Hans-Jürgen Sasse (eds.), 113134. Berlin: Akademie Verlag.

Payne, Thomas E.

1997 Describing Morphosyntax. A Guide for Field Linguists. Cambridge: Cambridge University Press.

Queixalós, Francesc

2006 The primacy and fate of predicativity in Tupi-Guaraní. In Root Classes and Lexical Categories in Amerindian Languages, Lois, Ximena and Valentina Vapnarsky (eds.), 249-287. Vienna: Peter Lang.

Queixalós, Francesc (ed.)

2001 Des noms et des verbes en tupi-guarani: état de la question. Munich: LINCOM EUROPA.

Sasse, Hans-Jürgen

1991 Predication and sentence constitution in universal perspective. Semantic universals and universal semantics, Dietmar Zaefferer (ed.), 75-95. Berlin, New York: Foris.

1993 Syntactic categories and subcategories. In Syntax. An International Handbook of Contemporary Research (Vol. 1), Jacobs, Joachim; Arnim von Stechow, Wolfgang Sternefeld and Theo Vennemann (eds.), 646-686. Berlin/New York: de Gruyter.

Schachter, Paul 
20 Katharina Haude

1985 Parts-of-speech systems. In Language Typology and Syntactic Description, Vol. 1: Clause Structure, Shopen, Timothy (ed.), 3-61. Cambrigde: Cambridge University Press. Zúñiga, Fernando

2006 Deixis and alignment. Inverse systems in indigenous languages of the Americas. Amsterdam/Philadelphia: Benjamins. 